\title{
A NEW FORM OF DROPPING FLASK.
}

\author{
By F. Y. Ponr.
}

It is often convenient in methods of titration in the laboratory to make use of a flask or bottle from which the standard solution can be poured or dropped and the amount of solution which has been used, determined by weighing the flask or bottle of liquid before aud after the operation. This method has several advantages over the ordinary volumetric one in which a burette is used, the first advantage being that of using the liquid at any ordinary temperature without making a correction for the difference between that temperature and the one at which the liquid was standardized, provided, of course, that the standardizing was made with the flask and not with a burette.

This is due to the simple fact that a gramme of water or any other liquid weighs the same, no matter whether the temperature be $15^{\circ} \mathrm{C}$. or $20^{\circ} \mathrm{C}$, and if, in process of standardizing, for example, a solution of $\mathrm{AgNO}_{3}$, it is found that one gramme of the solution is equivalent to one milligramme $(.001 \mathrm{grm}$.) of $\mathrm{Cl}$, we may use the solution (by weight) afterwards at the sime temperature or any other temperature ordinarily found in the laboratory without making any correction $f(r)$ the same. 'This is not the casc in using an ordinary burette and realing off the nolume taken, for here we must make use of a table of corrections for temperature, which would give us for a range of $10^{\circ} \mathrm{C} .--a y$, between $25^{\circ} \mathrm{C}$ and $13^{\circ} \mathrm{C}$, a difference of .2 of $1 \%$ of the strength. That is to say, if 100 c.c. of the sail solution are equivalent to $.100 \mathrm{grm}$. of $\mathrm{Cl}$, at $25^{\circ} \mathrm{C}$. the sarue volume of the liquid at $15^{\circ} \mathrm{C}$. would be equivalent to $.1002 \mathrm{Cl}$. Of course this applies to all burettes which record the rolume of liquid taken.

In the second place the dropping flask has an advantage over burettes which requile the use of a pinchoock and rubber tube, inaswuch as we may umploy in the Hask a solution such as permanganate of potash or chromic acid which would act injuriously upon the rubber tube and become itself recomposed. To obriate this difficulty in the use of burettes, recourse is had to glass stopcocks, which art expensive and not always perfect. They are also liable to stick very tightly if allowed to remain for some time in contact with $\mathrm{K} I \mathrm{OO}$ or Na HO solution.

The Gay Lussac and Bink burettes are not open to the second 
objection, but they are attended with a difficulty which is peculiarly their own, namely, the retention of a drop of the solution at the end of the dropping tube by capillary attraction and the prevention of the free delivery of the contents of the burette.

Analysts have overcome this difficulty by inserting a stopper, provided with a glass tube and rubber month tube, into the tol of the burette and expelling the refractory drop with the breath.

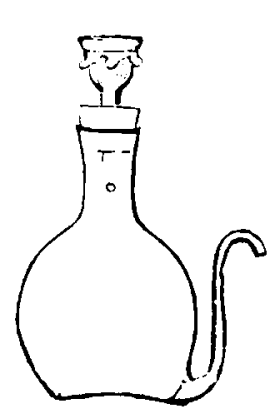
'This procedure answers very well, but there is a somewhat neater way as we shall see further on. The dropping flasks in use at the present day are few in kiud and very simple, being nothing but small flasks of varying capacity provided with a top or side tube and open to the objection which is found in using the burettes of Gay Lussac and Bink. The flask here shown is an improvement upon existing forms, and has been used for some time in the laboratory and with a great deal of satisfaction. It consists of a light, flat-hottomed flask of a size determined by the capaeity of the balance upon which it is to be weighed. From one side, near the bottom, a narrow tube starts and reaches up a little higher than the body of the flask, being then turned outward like the side tube of Gay Lussac's burette, which it resembles. In the neck of the flask a snall hole is blown which, during the operation of dropping, is governed by the thumb of the manipulator. Into the neck of the flask a rubber stopper is fitted and through this stopper a short thistle-tube is passed, the upper part of the latter being covered by a piece of thin sheet rubber, securely fastened by a piece of thread. The flask being filled with the standard solution is first counterpoised on the balance. It is then grasped aruund the neck, the thumb being placed very near the small hole in the side and the lorefinger held just over the rubber membrane on the top.

The flask is then tipped so as to deliver the solution through the side tube, the rapidity of flow being governed by the thumb, which closes the small hole in the neck at will. If at any time during the operation a drop is formed at the end of the tube, it can easily be forced out or drawn back into the flask by the control 
of the thumb and foretinger. By this means any amount of delivery may be obtained from palt of a drop (by touching the end of the tube to the stirring rod) to a steady stream.

After a sufficient quantity of the solution has been used, its weight is detecmined by $r$ placing the flask upon the balance pan and adding weights to balance the counterpoise in the other pan. In our own laboratory we use for this purpose a balance whose capacity is 500 grammes in each pan, and a counterpoise consisting of a small pasteboard box partly filled with shot. With this it is the work of only a few seconds to counterbalance the flask, and after the titration is completed, the amount of solution used is quickly ascertained by the above method of leaving the counterpoise as it was and adding weights to the pan containing the flask. The capacity of the latter is about 250 c.c. and one filling suffices for several operations, the counterpoise being changed each time by removing some of the shot.

The convenience of this modified volumetric method can be appreciated by those who usually bave a number of determinations of one kind to make in a lay, and it will recommend itself to all on account of the ease of manipulation, accuracy, and slight cost of the apparatus.

The adaptation of the above described contrivance to a Gay Lussac burette, is obvious. All that is necessary is to adapt a rubber stopper and thistle-tube to the burette, and to blow or drill a small hole into the side of the burette about an inch from the top.

The flasks used were made by William Baetz, 96 Fulton Street, New York.

\section{NOTE ON OIL OF MALT. \\ By Narcisse Pigeon. (Abstract.)}

beer is properly manufactured from malt and hops, barley being the grain usually employed in making malt. None of the substitutes for barley malt, contain the characteristic oil of malt and lack therefore the proper taste and aroma. Oil of malt has been found by the author in the radicles or rootlets of barley malt. and he suggests its extraction as a proper substance for developing the taste which is lacking in beer made from the abovementioned substances. 